\title{
Students Respond To The Use Of Instructional Technology In The Accounting Information Systems Classroom
}

\author{
Betty A. Kleen, (Email: is-bak@Nicholls.edu), Nicholls State University \\ L. Wayne Shell, (Email: mnmk-1ws@Nicholls.edu), Nicholls State University \\ Benny R. Zachry, (Email: acbl-bz@Nicholls.edu), Nicholls State University
}

\begin{abstract}
A SERVQUAL-inspired instrument measured students' satisfaction with technology tools used in AIS classrooms; 151 students in six schools participated. Student in-class computer activities generated the highest satisfaction among students, live software demonstration the least. Satisfaction varied little by gender or age group. Student in-class computer activities showed the most reaction of satisfaction to usage rates, and in all cases greater usage led to higher satisfaction. In some instances, the satisfaction score for a question differed across technology groups, but these differences are not generalizable. Factor analysis largely supports the a priori loading of satisfaction items into five SERVQUAL dimensions
\end{abstract}

\section{Introduction}

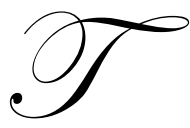

his study involved the assessment of student satisfaction with technology tools used in the Accounting Information Systems (AIS) classroom. Only limited empirical research exists related to how students perceive they benefit from the technology faculty elect to use in their classrooms. As institutions of higher education seek ways to gain a competitive advantage, high service quality becomes an important factor to address. Looking at student perception of benefits as a measure of the quality of service in the classroom can assist faculty and administrators.

Because the AIS course at many schools is one of the newer additions to the accounting curriculum, there is perhaps less received doctrine about how the course is or should be taught. AIS faculty are often able to experiment with new and different and non-traditional teaching methods, including, but not limited to multi-media presentations, live software demonstrations, live Internet connections, and student hands-on computer activities. Prior research by Kleen, Shell, and Zachry (1998) reported fairly high levels of instructional technology being used in the AIS classroom.

Parasuraman, Zeithaml, and Berry (PZB), developed the SERVQUAL instrument as a 22-item, two-part scale $(1988,1991)$. PZB identified five dimensions of service quality: Reliability, Responsiveness, Empathy, Tangibles, and Assurance. Since its inception, SERVQUAL has become a popular method of measuring customer service quality. Buttle (1996) noted SERVQUAL is based on the premise that an organization can best analyze service quality by considering it from the point of view of consumers. His review of SERVQUAL related literature, however, identified no articles applying the instrument to the classroom setting.

Modifications and adaptations of the SERVQUAL instrument are widespread; in fact, even the instrument's originators have tested modified versions (Zeithaml, Berry, and Parasuraman, 1996).

Readers with comments or questions are encouraged to contact the authors via e-mail. 
Researchers such as Teas (1994), and Brown, Churchill, and Peter (1993) offer support for the use of only the perceptions component of the SERVQUAL structure, eliminating the expectations component. A Van Dyke, Kappelman, and Prybutok 1997 article further concluded that using a single measure of service quality across industries is not feasible; they suggested that future research should involve development of industry-specific measures of service quality.

The current researchers replicated a study by Kleen, Shell, and Cox (1999), in which they developed and tested an instrument inspired by SERVQUAL. Kleen, Shell and Cox developed a 20-item instrument to measure student satisfaction with technology in the education environment, specifically business classrooms in colleges and universities. Their instrument and methodology eliminated the use of gap-based scores of perception versus expectations (P-E gap scores) of the original SERVQUAL, and focused only on perceptions of students as consumers. The 1999 study, which involved students in economics, marketing, information systems, and business communication classrooms, revealed that students in the various disciplines did have different levels of satisfaction with various technologies such as overhead transparencies, computer slide shows, software demonstrations, and student in-class computer activities. Satisfaction varied little by gender or by respondent age group, although satisfaction varied with intensity of technology use in some ways. MIS students were more satisfied than other students with in-class computer activities.

\section{Purpose}

"How satisfied are the student consumers of instructional technology being used in the accounting information systems classroom?" This question forms the basis for the study. When instructional technologies are used in the classroom, do students believe they learn more? Pay attention better? Do they believe they become more confident about their learning? Understand more? Do certain technologies generate higher satisfaction than others? Are there specific areas of consumer satisfaction in which one technology out performs another? Related issues include measuring student satisfaction with these and other items by gender and age group.

\section{Methodology}

The researchers used an instrument designed and administered in a 1999 study of student satisfaction with classroom technology by Kleen, Shell, and Cox. The instrument contained 20 questions inspired by SERVQUAL that focused on the perceptions of students as consumers of classroom instructional technology; the items did not include student expectations of desired or adequate service. This variation from the original SERVQUAL instrument is supported in the literature.

The original contact group for the study included all instructors who participated in the August 1999 AIS Educators Conference. Twenty AIS instructors initially agreed to administer the survey during the Fall 1999 term; these instructors each received survey instruments and response forms for all students in their AIS classrooms. In addition to questions focusing on student satisfaction, the instrument requested classification variables of gender, major, student class level, and age group. Seven different classroom instructional technologies, identical to the technologies used in the Kleen, Shell, and Cox 1999 study, established the primary focus of the instrument:

\footnotetext{
- $\quad$ Overhead transparencies on acetates

- $\quad$ Electronic slide shows

- Live software demonstrations

- $\quad$ Live Internet connections

- $\quad$ Videotape or television programs

- $\quad$ CD-ROM, laserdisc, or multimedia presentations

- $\quad$ Student in-class computer activities

-

Each instructor selected two of the seven technologies used in his or her classroom and directed students to answer the question sets for only those two technologies. Parallel sets of 20 questions were presented for each instructional technology.
} 
Nineteen of the twenty items, built around the five SERVQUAL dimensions of Tangibles, Reliability, Responsiveness, Assurance, and Empathy, were designed with a five-point response scale, with answer options ranging from strongly agree (1) to strongly disagree (5). Students also reported their estimate of the percentage of the class meetings in which the technology was used. The 20 items for computerized (electronic) slideshows are listed below and replicate those in Kleen, Shell and Cox (1999). On the data collection instrument, analogous questions were used for each of the other six technologies in the study.

1. $\quad$ The use of_(computerized slide shows)_made it easy to see the material presented.

2. $\quad$ The use of_(computerized slide shows)_was not appropriate in this class.

3. $\quad$ The use of_(computerized slide shows)_ helped me learn the material presented.

4. The use of_(computerized slide shows)_ was a good way to reinforce assigned reading material.

5. $\quad$ The use of_(Computerized slide shows)_worked when it was supposed to.

6. $\quad$ The use of_(computerized slide shows)_ helped me pay attention in class.

7. The use of_(computerized slide shows)_was distracting.

8. $\quad$ The use of_(computerized slide shows)_ helped make this course more interesting.

9. The use of_(computerized slide shows)_allowed me to focus better on what the professor was saying.

10. The use of_(computerized slide shows)_was more trouble than it was worth.

11. The use of_(computerized slide shows)_made me more confident about what I was learning.

12. The use of_(computerized slide shows)_ helped me to better understand fundamental course concepts.

13. The use of_(computerized slide shows)_tended to oversimplify lectures.

14. The use of_(computerized slide shows)_helped me "keep up" with lecture.

15. The_(computerized slide shows)_ used in this class were visually appealing.

16. The use of_(computerized slide shows)_ helped me organize my lecture notes.

17. The use of_(computerized slide shows)_ helped me understand the lecture material.

18. The use of_(computerized slide show)_is a modern, up-to-date lecture method.

19. I I wish more of my instructors used__(computerized slide shows)_in their classes.

20. The use of_(computerized slide show)__was used in approximately _ percent of the meetings of this class.

Since items 2, 7, 10, and 13 were negative in nature, absolute scores of these items were inverted to be comparable with positively worded items during data analysis. Mean scores were calculated for each of the 20 items, in each of the technology groups, in the aggregate, and in various subgroups such as mean scores by gender and mean scores by age. Cross tabs of satisfaction level versus frequency of use for each of the 19 items were also calculated. The researchers used these descriptive statistics to illustrate:

- Which of the 19 satisfaction-scored items showed the highest satisfaction in each of the technology groups? Which the lowest?

- $\quad$ For which items among 1 - 19 do satisfaction scores rise as the technology is used more frequently? For which do satisfaction scores fall?

- $\quad$ For each of the 19 items, what of the seven technologies had the "most satisfied" results? "Least satisfied" results?

- Among the 19 satisfaction-scored items, which of the seven technologies were more often represented in the "most satisfied" and "least satisfied" outcomes?

The descriptive results were supplemented by hypothesis tests using ANOVA, simple regression, and multiple regression. ANOVA tested whether group means were equal. Simple and multiple regression models were used to measure impact of different frequencies of use. In the multiple regression model age and gender were classification variables. Factor analysis was conducted to determine how closely items related to the five SERVQUAL dimensions.

\section{Findings}

The findings section of the paper is organized into sections addressing simple descriptive statistics; group ANOVAs; simple linear regression and multiple linear regressions of satisfaction levels versus usage, controlled for age and gender; and finally, factor analysis. 


\section{Descriptive Statistics}

Faculty at six schools administered and returned questionnaires, resulting in 151 usable responses from six distinct classes. Class size ranged from 21 to 31 . Each faculty member selected two of the seven technology sections for his or her students to answer; the number of students responding to each section of the questionnaire is listed in Table 1. No faculty member selected CD-ROM/multimedia presentations for students to answer. Interestingly, this same technology went unused in the Kleen, Shell, and Cox 1999 study.

\section{Table 1}

\section{Students Responding to Each Technology Group}

\begin{tabular}{|l|c|c|}
\hline \multicolumn{1}{|c|}{ Technology Group } & No. of Respondents & No. of Classes \\
\hline A. Overhead Transparencies & 26 & 1 \\
\hline B. Electronic Slideshows & 80 & 3 \\
\hline C. Live Software Demonstrations & 72 & 3 \\
\hline D. Live Internet Connections & 26 & 1 \\
\hline E. Videotape or Television Program & 21 & 1 \\
\hline F. CD-ROM/Multimedia Presentations & 0 & 0 \\
\hline G. Student In-Class Computer Activities & 77 & 3 \\
\hline Total (151 respondents, 2 technology choices) & 302 & \\
\hline
\end{tabular}

Sixty-three percent of the students were under the age of twenty-five, $29.8 \%$ were 25 and over, and $7.3 \%$ did not report age. Females represented $58 \%$ of the 134 students who reported gender. Of those reporting student classification, $95 \%$ were either junior or seniors.

Within each technology, the lowest item score (most favorable rating) and highest item score (least favorable rating) were identified. For example, within electronic slideshows, the most favorable rating was item 18 , "modern, up-to-date method," with a mean of 1.85. Within this same technology, the least favorable rating was item 8 , "helped make course more interesting," with a mean of 2.93. Similar comparisons were made for the remaining technologies. These results appear in Table 2.

The lowest average (highest satisfaction) among all items and all technology groups was within student inclass computer activities, item 2, "technology appropriate for the class," (1.76). The highest average among all items and all groups (least favorable rating) was software demonstrations, item 16, "helped organize lecture notes," (3.30). That is, live software demos were not seen as an effective organizing device from the students' perspective.

Table 3 includes a breakdown of highest and lowest score for each satisfaction item, comparing across the six technologies. For example, for item 3, "Helped me learn material presented," the lowest score of 2.03 (highest satisfaction) was in the student in-class computer activities group. The highest score of 2.76 (lowest satisfaction) for that same item was in the videos or TV programs group.

Table 2

Items Receiving Highest and Lowest Satisfaction Ratings by Technology

\begin{tabular}{|l|l|l|l|c|}
\hline \multicolumn{1}{|c|}{ Technology } & \multicolumn{1}{|c|}{ Highest Satisfaction Item } & Score & Lowest Satisfaction Item & Score \\
\hline $\begin{array}{l}\text { A.Overhead } \\
\text { Transparencies }\end{array}$ & $\begin{array}{l}\text { 2. Technology appropriate for the } \\
\text { class } \\
\text { 3 Helped me learn material }\end{array}$ & 2.07 & $\begin{array}{l}\text { 18. Modern, up-to-date } \\
\text { method }\end{array}$ & 3.08 \\
\hline $\begin{array}{l}\text { B.Electronic Sli- } \\
\text { deshows }\end{array}$ & 18 Modern, up-to-date method & 1.85 & $\begin{array}{l}\text { 8. Helped make course } \\
\text { more interesting }\end{array}$ & 2.93 \\
\hline $\begin{array}{l}\text { C. Live Software } \\
\text { Demos }\end{array}$ & $\begin{array}{l}\text { 2. Technology appropriate for the } \\
\text { class }\end{array}$ & 1.82 & $\begin{array}{l}\text { 16. Helped organize lecture } \\
\text { notes }\end{array}$ & 3.30 \\
\hline
\end{tabular}




\begin{tabular}{|l|l|l|l|c|}
\hline $\begin{array}{l}\text { D. Live Internet } \\
\text { Connections }\end{array}$ & $\begin{array}{l}\text { 8. Helped make course more in- } \\
\text { teresting }\end{array}$ & 1.81 & $\begin{array}{l}\text { 13. Oversimplified lectures } \\
\text { (negatively phrased) }\end{array}$ & 3.00 \\
\hline $\begin{array}{l}\text { E. Videos or TV } \\
\text { programs }\end{array}$ & 10. Was worth the effort in using & 1.95 & $\begin{array}{l}\text { 4. Good way to reinforce } \\
\text { assigned reading material }\end{array}$ & 2.81 \\
\hline F. CD-ROM, etc. & N/A & N/A & N/A & N/A \\
\hline $\begin{array}{l}\text { G. Student In- } \\
\text { Class Computer } \\
\text { Activities }\end{array}$ & $\begin{array}{l}\text { 2. Technology appropriate for the } \\
\text { class }\end{array}$ & 1.76 & $\begin{array}{l}\text { 16. Helped organize lecture } \\
\text { notes }\end{array}$ & 3.16 \\
\hline
\end{tabular}

Table 3

Highest and Lowest Satisfaction Scores by Satisfaction Item

\begin{tabular}{|c|c|c|c|c|}
\hline \multirow{2}{*}{ Satisfaction Item } & \multicolumn{2}{|c|}{ Highest Satisfaction } & \multicolumn{2}{|c|}{ Lowest Satisfaction } \\
\hline & Technology & Score & Technology & Score \\
\hline 1. Made easy to see material presented & $\mathrm{B}$ & 1.90 & $\mathrm{E}$ & 2.33 \\
\hline 2. Appropriate for the class & $\mathrm{G}$ & 1.76 & $\mathrm{D}$ & 2.12 \\
\hline 3. Helped me learn material presented & $\mathrm{G}$ & 2.03 & $\mathrm{E}$ & 2.76 \\
\hline 4 Good way to reinforce assigned reading material & $\mathrm{B}$ & 2.04 & $\mathrm{E}$ & 2.81 \\
\hline 5. Worked when it was supposed to & $\mathrm{E}$ & 2.00 & A & 2.32 \\
\hline 6. Helped me pay attention & $\mathrm{G}$ & 2.29 & $\mathrm{~B}$ & 2.82 \\
\hline 7. Distracting technology & $\mathrm{B}$ & 2.05 & $\mathrm{D}$ & 2.54 \\
\hline 8. Helped make course more interesting & $\mathrm{D}$ & 1.81 & $\mathrm{~B}$ & 2.92 \\
\hline $\begin{array}{l}\text { 9. Allowed me to focus better on what the profes- } \\
\text { sor was saying }\end{array}$ & B & 2.29 & $\mathrm{E}$ & 2.71 \\
\hline 10. Technology worth the trouble & $\mathrm{E}$ & 1.95 & A & 2.50 \\
\hline $\begin{array}{l}11 \text { Made me more confident of what I was } \\
\text { learning }\end{array}$ & G & 2.24 & A,D (tie) & 2.73 \\
\hline $\begin{array}{l}\text { 12.Helped me better understand fundamental } \\
\text { course concepts }\end{array}$ & B & 2.29 & $\mathrm{C}$ & 2.85 \\
\hline 13. Oversimplified lectures & $\mathrm{E}$ & 2.24 & $\mathrm{D}$ & 3.00 \\
\hline 14. Helped me keep up with lectures & $\mathrm{A}$ & 2.27 & $\mathrm{C}$ & 2.86 \\
\hline 15. Visually appealing & $\mathrm{D}$ & 2.08 & $\mathrm{~B}$ & 2.73 \\
\hline 16. Helped me organize lecture notes & $\mathrm{B}$ & 2.27 & $\mathrm{C}$ & 3.30 \\
\hline 17. Helped me understand lecture material & $\mathrm{B}$ & 2.33 & $\mathrm{C}$ & 2.68 \\
\hline 18. Modern, up-to-date lecture method & $\mathrm{D}$ & 1.85 & $\mathrm{~A}$ & 3.08 \\
\hline $\begin{array}{l}\text { 19. Wished more instructors used same technolo- } \\
\text { gy }\end{array}$ & $\mathrm{D}$ & 2.19 & A & 3.04 \\
\hline 20. Amount of class usage & $\mathrm{D}$ & 2.71 & $\mathrm{E}$ & 4.43 \\
\hline
\end{tabular}

Student in-class computer activities (Group G) had 4 of the 19 "highest satisfaction" and no "lowest satisfaction" items. Electronic slideshows (Group B) had the greatest number of "highest satisfaction" items (7); but it also had 3 "lowest satisfaction" items, including "helped make course more interesting." Live software demonstrations (Group C) had no "highest satisfaction" and 4 "lowest satisfaction" items. Overhead transparencies (Group A) had only 1 "highest satisfaction" and 4.5 "lowest satisfaction" items. For item 20, the low score 2.71 (implies a usage rate slightly under 50\%) occurred for technology D, live Internet connection.

\section{Group ANOVA}

The researchers now used ANOVA to test for differences among the 19 satisfaction-based items, with technology as the factor. The general hypothesis reads, "Is the average score for item X equal among all seven technologies, or are there significant differences among the seven technologies for item X?" This hypothesis is repeated for all 19 items. The mean difference among technologies was significant for items $3,4,6,8,11,12,13,14$, 16,18 , and 19. Levene's test for homogeneity of variances suggested that in almost all cases, equality of variances could be assumed. 
ANOVA revealed significant differences for item 4 and item 6. Post hoc comparisons revealed that for item 4, technology Group B, electronic slideshows, was greater, or more satisfied, than Group C, live software demonstrations. In the post hoc comparisons for item 6, Groups B and G differed significantly. Students were less satisfied with electronic slideshows than with in-class computer activities regarding the item "helped me pay attention in class." Finally, electronic slideshow technology respondents were less satisfied than those students responding to live Internet connections and student in-class computer activities on the item "makes the course more interesting."

Students were less satisfied with live software demonstrations than with electronic slideshows and in-class computer activities regarding the item "helped me understand fundamental course concepts." Students responding to Internet connections were less satisfied than student in-class computer activities in relation to the question concerning oversimplification of lectures. Visual appeal generated higher satisfaction levels from the electronic slideshow group than from the student in-class computer activities group; students responding to live software demonstrations were less satisfied than students responding to live Internet connections for this same question. Students responding to the overhead transparency technology were less satisfied with this technology as an up-to-date lecture support than were students in all other reporting technology groups. The overhead transparency respondents were also less likely to wish more instructors used that technology than the group using student in-class computer activities. There were no significant pairings for the questions related to learning the material presented, making the student more confident about what he/she was learning, or helping the student keep up with lecture.

\section{Satisfaction Versus Usage}

To test whether student satisfaction with information technology varied with the frequency of technology use, the researchers postulated a simple linear regression model for each technology.

$S_{i j}=a+b \cdot X_{20 j}$

where $S_{i j}=$ average satisfaction of respondent $\mathrm{j}$ on item I and $\mathrm{X}_{20 \mathrm{j}}=$ usage score of respondent $\mathrm{j}$

Within the overhead transparency technology (Group A), no items were significant. Item 1, "Made it easy to see material presented," and item 15, "visually appealing," were significant within electronic slideshow technology (Group B). For live Internet technology (Group D) item 2, "appropriate technology for the class," and item 4, "good way to reinforce assigned reading material," were significant. Within videotape or TV technology (Group E), item 18, "modern up-to-date lecture method," was significant. Finally, within student in-class computer activities (Group G), items 3, 6, 8, 9, 11, 12, 14, 16, and 17 were significant. All slopes of significant regressions were negative. For most items, satisfaction was unrelated to frequency of technology use. For those occasional instances of significance, greater usage resulted in higher satisfaction. This supports the Kleen, Shell, and Cox 1999 results.

\section{Multiple Regression}

As usage rates vary, males and females might have different satisfaction response patterns; that is, male and female respondents have unlike regression slopes. To test this concern, the researchers built two simple linear regression models for each of the 19 items: one for male respondents and one for female respondents. These regressions were conducted for each item and technology combination where a significant difference in satisfaction means had already been established.

No case was found where the regression of male students was significant and where the regression of females on the same item was also significant. If the overall regressions were not significant, then the slopes of the regressions have no meaning. On the basis of this lack of difference between male respondent behavior and female respondent behavior, the researchers included gender as a conventional classifying variable. The resulting dummy variable would detect differences in regression intercept, now that it has been established that there is no difference in slope. 
The researchers then conducted multiple regressions to explain satisfaction ratings. The dependent variable was satisfaction rating for each of the 19 items. One independent variable was item 20 (usage rate); other independent variables were gender and age.

Within the overhead transparency group (technology A), only two of the 19 regressions, "made me more confident of what I was learning," and "helped me keep up with lectures," were significant. The only significant variable was age. Within the electronic slideshow group (technology B), only the item, "made it easy to see material presented," was significant. Gender and frequency of use, but not age, were significant variables. Female respondents rated the item more favorably than did males. Within frequency of use, greater use led to a more favorable rating. Within the live software demos group (technology C), only "good way to reinforce assigned reading material," showed a significant regression. All three variables were significant. For this item, older students generated more favorable responses; females generated more favorable responses; responses became more favorable with increased frequency of use. There were no findings of significance in either live Internet connections (technology D), or videos or TV Programs (Technology E).

Within the student in-class computer activities group (technology G), "helped me see materials presented," "made me more confident of what I was learning," and "helped me better understand fundamental course concepts," gender and amount of usage were significant. Female respondents gave more favorable ratings. More favorable ratings came with higher usage levels. For "helped me pay attention," all three variables were significant. Older students gave less favorable ratings; female students gave more favorable ratings; higher frequency of use generated more favorable ratings.

\section{Factor Analysis}

The researchers used factor analysis, a data reduction method to reduce 18 items to a smaller number of factors. (The 19th item, written as a global satisfaction item, was excluded from this analysis). The researchers' $a$ priori expectation, base on the theory of SERVQUAL, was that the 18 variables would load onto 5 factors. The 18 satisfaction items were created in an attempt to measure consumer satisfaction in each of the five dimensions of the original SERVQUAL. Ideally, the data reduction will reveal five factors that relate neatly to the five SERVQUAL dimensions. In fact, other researchers have found use of SERVQUAL seldom reveals all five factors.

The researchers used the Kleen, Shell, and Cox 1999 a priori loadings and placed items 1 through 18 items into the five SERVQUAL dimensions as follows: Reliability, items 2, 5, and 10; Empathy, items 12, 16, and 17; Responsiveness, items 8, 9, 13, and 14; Tangibles, items 1, 7, 15, and 18; and Assurance, items 3, 4, 6, and 11.

The researchers used the rotated component matrix within SPSS's data reduction tools. The result of this analysis was a separate set of loadings for each of the six technology tools. Table 4 displays the researcher-assigned loadings for each of the six technologies. For example, variables 2, 3, 4, 7, 10, and 17 loaded onto the first factor for the overhead transparencies technology. The final step in this analysis was to determine whether five factors emerged for each technology, whether the loadings match the five factors, whether the loadings match the a priori assignments, and whether the loadings are similar from one technology to another. 
Table 4

Variable Loadings by Instructional Technology

\begin{tabular}{|c|c|c|c|c|c|c|}
\hline \multirow[b]{2}{*}{ Factor } & \multicolumn{6}{|c|}{ Classroom Technology } \\
\hline & $\begin{array}{l}\text { Overhead } \\
\text { Transpa- } \\
\text { rencies }\end{array}$ & $\begin{array}{l}\text { Electronic } \\
\text { Slideshows }\end{array}$ & $\begin{array}{lr}\text { Live } & \text { Soft- } \\
\text { ware } & \text { De- } \\
\text { mos } & \\
\end{array}$ & $\begin{array}{l}\text { Live Internet } \\
\text { Connections }\end{array}$ & $\begin{array}{l}\text { Videotape/ } \\
\text { Television }\end{array}$ & $\begin{array}{l}\text { Student In-class } \\
\text { Computer Ac- } \\
\text { tivities }\end{array}$ \\
\hline $\begin{array}{c}\text { No. of } \\
\text { Factors }\end{array}$ & 6 & 5 & 4 & 5 & 2 & 3 \\
\hline I & $\begin{array}{c}2,3,4,7 \\
10,17\end{array}$ & $\begin{array}{c}1,3,4,8,9 \\
11,12,17\end{array}$ & $\begin{array}{c}1,3,4,5,9 \\
11,12,14 \\
16,17\end{array}$ & $1,3,4,14,15$ & $\begin{array}{l}1,3,4,6,8,9 \\
11,12,16,17\end{array}$ & $\begin{array}{l}1,2,3,4,6,8 \\
10,11,12,15\end{array}$ \\
\hline II & $4,6,9$ & $6,15,18$ & $6,7,8,9,10$ & $\begin{array}{c}8,9,13,15,16 \\
17\end{array}$ & $\begin{array}{c}2,5,7,10,13 \\
14,15,18\end{array}$ & $\begin{array}{c}5,9,14,15,16 \\
17\end{array}$ \\
\hline III & $11,12,14$ & $\begin{array}{c}7,9,10,14 \\
16\end{array}$ & $8,15,18$ & $6,9,10,11,12$ & & $7,10,13,18$ \\
\hline IV & $\begin{array}{c}15,16,17, \\
18\end{array}$ & $1,2,5,10$ & 2,13 & 2,7 & & \\
\hline $\mathbf{V}$ & 8,18 & 13 & & $1,5,18$ & & \\
\hline VI & 1 & & & & & \\
\hline
\end{tabular}

The data reduction for overhead transparencies identified six factors, not five. Electronic slideshows and live Internet did identify five factors. The remaining technologies had fewer factors.

Did the loadings match a priori expectations? For instance, did items 2, 5, and 10, the Reliability dimension, appear in the same loadings? Two and 10, but not 5, loaded together in overhead transparency technology; 25 , and 10 loaded together on electronic slideshows; 2 and 5, but not 10 loaded together for live software demonstrations. Items 2, 5, and 10 loaded onto three different factors for live Internet connection; 2, 5, 10 and loaded onto the same factor for live TV, and finally, 2 and 10, but not 5, loaded together for student in-class computer activities. The researchers concluded that these were more similar than they were different and that the data did match the Reliability dimension. This would mean that for electronic slideshows, Factor IV represented Reliability, while Reliability would be contained within Factor II for videotape/TV.

In a second example, the Empathy dimension included items 12, 16, and 17. Those three items loaded together on live software demonstrations and on videotape/TV, as part of a larger factor. Sixteen and 17 loaded together on overhead transparencies, live Internet, and student in-class computer activities. Items 12 and 17 loaded together for electronic slideshows. Again, the researchers concluded that these similarities suggest that the Empathy factor had been identified. While these three items may have loaded together, they were often part of a larger factor, suggesting that Empathy could not be separated from some other influences. The Assurance dimension was equally well behaved.

\section{Conclusions and Recommendations}

The researchers measured students' satisfaction with a broad spectrum of classroom technology tools, using an instrument designed by Kleen, Shell, and Cox. Faculty from six schools administered the instrument to 151 students in AIS classes.

For student in-class computer activities, live software demonstrations, and overhead transparencies, the item "technology appropriate for the class" received highest satisfaction. For live Internet connections, the item, "helped make course more interesting," received the highest satisfaction rating. In contrast, for electronic slideshows, the same item earned a lowest satisfaction rating within that technology. The electronic slideshow respondents were less satisfied than the student in-class computer activities group regarding "helped me pay attention in class." Some other scattered instances of differing means across technologies also existed. As found in an earlier 
study by Kleen, Shell, and Cox, satisfaction varied little by gender or age group; likewise, the current study also found satisfaction appeared to rise with greater use of a technology in the instances where satisfaction was related to frequency of use.

Based on the number of items for which each technology scored highest or lowest satisfaction, AIS instructors are encouraged to make greater use of student in-class computer activities and electronic slideshows, and perhaps surprisingly, less use of live software demonstration. Three of the four items with the lowest satisfaction scores for live software demonstrations fell in the researchers' a priori empathy dimension of SERVQUAL. Instructors should be aware of the limitations of this technology, in particular that students may have difficulty relating the demonstrations to course concepts.

The factor loadings for each of the technology tools resulted in multiple factors identified for each technology. The results generally matched the Reliability, Empathy, and Assurance dimensions of the Kleen, Shell, and Cox a priori assignment of satisfaction items, although as in other SERVQUAL studies, five clearly defined factors did not emerge within each technology group.

\section{Suggestions for Future Research}

The researchers are convinced that there are good classroom technologies and inferior classroom technologies. The researchers are not convinced that gender plays as little a role in satisfaction scores as their small numbers indicate. The research dealt with the course, not individual topics in the course, and there may be different appropriate technologies for different topics and subtopics. Future studies relating to the role of gender in satisfaction scores and use of technology in various subcomponents of the AIS course can provide further insight on these issues.

\section{References}

1. Brown, Tom, Gilbert A. Churchill, and J. Paul Peter, "Improving the Measurement of Service Quality," Journal of Retailing, Vol. 69, No. 1, pp. 127-139, 1993.

2. Buttle, Francis A., "SERVQUAL: Review, Critique, Research Agenda," European Journal of Marketing, Vol. 30, No. 1, pp. 8-32, 1996.

3. Kleen, Betty, L. Wayne Shell, and Benny Zachry, "Measuring Student Satisfaction with Instructional Technology in Accounting Information Systems Classrooms," Decision Sciences Institute Southwest Region Proceedings, New Orleans, Louisiana, pp. 134-136, 2001.

4. Kleen, Betty, L.Wayne Shell, and K. Chris Cox, "Measuring Student Satisfaction with Instructional Technologies Across Business Disciplines," Proceedings of the International Academy for Information Management, Charlotte, North Carolina, pp. 142-152, 1999.

5. Kleen, Betty, L. Wayne Shell, and Benny Zachry, "Classroom Configuration and Instructional Technology Impact Teaching Methods," The Review of Accounting Information Systems, Vol. 3, No. 2, pp. 47-57, 1998.

6. Parasuraman, A., Valarie A. Zeithaml, and Leonard L. Berry, "Alternative Scales for Measuring Service Quality: A Comparative Assessment Based on Psychometric and Diagnostic Criteria," Journal of Retailing, Vol. 70, No. 3, pp. 201-230, 1994.

7. Parasuraman, A., Valarie A. Zeithaml, and Leonard L. Berry, "Refinement and Reassessment of the SERVQUAL Scale," Journal of Retailing, Vol. 67, No. 4, pp. 420-450, 1991.

8. Parasuraman, A., Valarie A. Zeithaml, and Leonard L. Berry, "SERVQUAL: A Multiple-item Scale for Measuring Consumer Perceptions of Service Quality." Journal of Retailing, Vol. 64, No. 1, pp. 12-40, 1988.

9. $\quad$ Teas, R.Kenneth, “Expectations, Performance Evaluations and Consumer Perceptions of Quality,” Journal of Marketing, Vol. 57, No. 4, pp. 18-35, 1993.

10. VanDyke, Thomas, Leon A. Kappelman, and Victor R. Prybutok, "Measuring Information Systems Service Quality: Concerns on the use of the SERVQUAL Questionnaire," MIS Quarterly, Vol. 21, No. 2, pp. 195209, 1997. 
11. Zeithaml, Valarie, Leonard L. Berry, and A. Parasuraman, "The Behavioral Consequences of Service Quality," Journal of Marketing, Vol. 56, No. 3, pp. 31-46, 1996.

Notes 